\title{
EFFECT OF MANGANESE ON MAGNETIC AND ELECTRICAL PROPERTIES OF THE RMn $\mathrm{T}_{12-x}$ ALLOYS
}

\author{
W. SUSKI ${ }^{a, b, *}$, K. WochoWSKI ${ }^{a}$, T. MYdLARZ $^{b}$ AND B. BeLAN ${ }^{c}$ \\ ${ }^{a} \mathrm{~W}$. Trzebiatowski Institute of Low Temperature and Structure Research \\ Polish Academy of Sciences, P.O. Box 1410, 50-950 Wrocław 2, Poland \\ ${ }^{b}$ International Laboratory of High Magnetic Fields and Low Temperatures \\ 53-421 Wrocław, Poland \\ ${ }^{c}$ Department of Inorganic Chemistry, Ivan Franko National University of L'viv \\ 790005 L'viv, Ukraine
}

\section{Devoted to memory of late E. Leyarovsky}

The magnetic and electrical properties of the tetragonal, $\mathrm{ThMn}_{12}$-type $\mathrm{RMn}_{x} \mathrm{~T}_{12-x}$ alloys $(\mathrm{R}=\mathrm{Y}, \mathrm{Ce}, \mathrm{Pr}, \mathrm{Nd}, \mathrm{Sm}$ and $\mathrm{T}=\mathrm{Fe}, \mathrm{Co}, \mathrm{Ni})$ were studied in broad temperature and magnetic field ranges to elucidate an influence of manganese on the magnetic ordering in these materials. Magnetic properties were examined at $T=1.7-300 \mathrm{~K}$ in magnetic field up to $14 \mathrm{~T}$, whereas the electrical properties were examined at $T=4.2-300 \mathrm{~K}$, on the polycrystalline samples. Majority of the samples exhibit ferro- or ferrimagnetic properties. Some samples containing larger concentration of $\mathrm{Mn}$ are paramagnetic in the whole temperature range. The electrical resistivity of these alloys shows metallic character.

PACS numbers: 75.20.-g, 75.20.En, 75.50.Ee, 75.50.Gg

\section{Introduction}

The magnetic properties of the $\mathrm{ThMn}_{12}$-type $f$-electron tetragonal ternaries containing rare earths and $3 d$ transition metals are of special interest because of their potential applications as permanent magnets (for review see [1]). Only very few binary compounds of this type are known but there is plenty of ternaries obtained with the $p$ electron elements ( $\mathrm{Si}, \mathrm{Al})$, early $3 d(\mathrm{Ti}, \mathrm{V}, \mathrm{Cr}, \mathrm{Mn}), 4 d(\mathrm{Zr}, \mathrm{Nb}$, $\mathrm{Mo})$ or $5 d(\mathrm{Ta}, \mathrm{W}, \mathrm{Re})$ metals as stabilizing components. However, compounds with $\mathrm{Mn}$ reported for $\mathrm{Fe}$ as transition element and in principle for heavier rare earths are not very popular [2-5]. A paper concerning $\mathrm{RCo}_{8} \mathrm{Mn}_{4}$ compounds in

\footnotetext{
*corresponding author; e-mail: suski@int.pan.wroc.pl
} 
which besides the heavier rare earths $\mathrm{Pr}$ and $\mathrm{Y}$ were used as $\mathrm{R}$ elements provides unique results for Co as transition element [6]. All these materials crystallize in the tetragonal $\mathrm{ThMn}_{12}$-type structure (I4/ $\mathrm{mmm}$ space group) in which the $2 \mathrm{a}$ site is occupied by rare earth atoms and $3 d$ atoms are located in the $8 f, 8 i$, and $8 j$ positions.

For $\mathrm{YMn}_{12-x} \mathrm{Fe}_{x}$ alloys the single phase samples were found for $0 \leq x \leq 6.7$, and for $x=4$ no long-range magnetic order was detected above $77 \mathrm{~K} \mathrm{[2].}$

The $\mathrm{RMn}_{12-x} \mathrm{Fe}_{x}$ alloys with $\mathrm{R}=\mathrm{Gd}, \mathrm{Tb}, \mathrm{Dy}$, and Ho exist as the single phase for $x \leq 8$. It is shown that the Néel temperature is almost independent of $\mathrm{R}$ and has a maximum at about $x=5$ [3] or 6 [4]. For $\mathrm{ErMn}_{12-x} \mathrm{Fe}_{x}$ alloys [4] at low temperature ferromagnetism is observed on Er atoms and the maximum $T_{\mathrm{C}}$ is detected for $x=4$. Abad et al. [5] claim that in the $\mathrm{RMn}_{12-x} \mathrm{Fe}_{x}$ (where $\mathrm{R}=$ $\mathrm{Tb}, \mathrm{Y}$ ) there are positive interactions for $\mathrm{Fe}$ and negative for Mn sublattices. Wang et al. [6] have reported that among the $\mathrm{RCo}_{8} \mathrm{Mn}_{4}$ alloys ( $\left.\mathrm{R}=\mathrm{Y}, \mathrm{Pr}, \mathrm{Gd}, \mathrm{Tb}, \mathrm{Dy}\right)$ the compounds of $\mathrm{Y}, \mathrm{Pr}$, and $\mathrm{Gd}$ are ferromagnetic whereas the compounds of $\mathrm{Tb}$ and Dy are considered as the ferrimagnetic with two magnetic sublattices.

At present, the compounds of light rare earths with $\mathrm{Fe}, \mathrm{Co}$, and $\mathrm{Ni}$ are reported for the first time, except for $\mathrm{PrCo}_{8} \mathrm{Mn}_{4}$ [6].

The goals of the present paper are as follows: the search for magnetic materials with favourable parameters for application, and the elucidation of the influence of $\mathrm{Mn}$ on the magnetic ordering of these materials, particularly, the modification of the two-sublattice model (see e.g. [7]) by the third (Mn) $3 d$ magnetic sublattice. The preliminary results of these investigations have been published recently [8].

\section{Experimental}

The $\mathrm{RMn}_{x} \mathrm{~T}_{12-x}$ alloys were prepared as it had been described previously [8]. The magnetic measurements were performed on a bulk pieces of polycrystalline material. The magnetic properties were investigated in principle in the temperature range 1.7-300 K using a SQUID magnetometer technique in magnetic field of $0.5 \mathrm{~T}$. Some samples have the magnetic transition temperature above room temperature (see Table). The magnetization was measured at $T=1.7 \mathrm{~K}$ in magnetic fields up to $5 \mathrm{~T}$ and at $T=4.2 \mathrm{~K}$ up to $14 \mathrm{~T}$. The electrical resistivity was studied at $T=4.2-300 \mathrm{~K}$ for polycrystalline samples of $\mathrm{Y}$ and $\mathrm{Ce}$.

\section{Results and discussion}

All the investigated samples are a single phase, tetragonal $T h M n_{12}$-type, with the lattice parameters presented in [9]. This structure type has only one position for the $f$ element (2a) but three positions available (8f, $8 \mathrm{i}$, and $8 \mathrm{j}$ ) for transition $(3 d)$ elements. The investigated samples form a variety of stoichiometric types, as it was also observed previously [2-5]. Most probably the reason for that is the close location of the contributing $3 d$ elements in the periodic table. The absence of $\mathrm{La}$ compounds, observed also previously $[3,6]$, seems to indicate that the La atom is too large to be located in the $\mathrm{ThMn}_{12}$-type crystal lattice. Due to the absence of 
TABLE

Magnetic data of the $\mathrm{RMn}_{x} \mathrm{~T}_{12-x}$ alloys.

\begin{tabular}{|c|c|c|c|c|c|}
\hline Alloy & $\begin{array}{c}\text { Magnetic } \\
\text { order } \\
? \\
\end{array}$ & $\begin{array}{c}\text { Transition } \\
\text { temp. } \\
T[\mathrm{~K}] \\
\end{array}$ & $\begin{array}{c}\text { Saturation } \\
\text { moment } \\
{\left[\mu_{\mathrm{B}} / \text { f.u. }\right]}\end{array}$ & $\begin{array}{l}\text { Effective } \\
\text { moment } \\
{\left[\mu_{\mathrm{B}} / \text { f.u. }\right]}\end{array}$ & $\begin{array}{c}\theta \\
{[\mathrm{K}]}\end{array}$ \\
\hline $\mathrm{YMn}_{5.1} \mathrm{Fe}_{6.9}$ & $\mathrm{C}$ & $T_{\max } \approx 48$ & 2.36 & 7.3 & 186.9 \\
\hline $\mathrm{Y}_{1,3} \mathrm{Mn}_{7.9} \mathrm{Fe}_{3.8}$ & $\mathrm{C}$ & $T_{\max } \approx 36$ & & & \\
\hline $\mathrm{CeMn}_{4.96} \mathrm{Fe}_{7.04}$ & $\mathrm{~F}$ & $\approx 230$ & 16.81 & & \\
\hline $\mathrm{CeMn}_{7} \mathrm{Fe}_{5}$ & $\mathrm{C}$ & $\begin{array}{c}T_{\max } \approx 36 \\
T_{\mathrm{C}} \approx 100\end{array}$ & & 8.16 & -43.1 \\
\hline $\mathrm{CeMn}_{9.65} \mathrm{Fe}_{2.35}$ & $\mathrm{P}$ & & & & \\
\hline $\mathrm{CeMn}_{4.16} \mathrm{Co}_{7.84}$ & $\mathrm{C}$ & $T_{\max } \approx 110$ & 4.08 & & \\
\hline $\mathrm{CeMn}_{5} \mathrm{Co}_{7}$ & $\mathrm{AF}$ & 41 & & & \\
\hline $\mathrm{CeMn}_{6.24} \mathrm{Co}_{5.76}$ & $\mathrm{AF}$ & $\begin{array}{c}4.5 \\
T_{\max } \approx 200\end{array}$ & & & \\
\hline $\operatorname{PrMn}_{5.6} \mathrm{Fe}_{6.4}$ & $\mathbf{P}$ & & & 5.26 & -3.7 \\
\hline $\operatorname{PrMn}_{5.2} \mathrm{Co}_{6.8}$ & $\mathrm{C}$ & $T_{\max }=53$ & 3.0 & 10 & 140 \\
\hline $\mathrm{NdMn}_{4} \mathrm{Co}_{8}$ & $\mathrm{~F}$ & $\approx 400$ & 6.87 & & \\
\hline $\mathrm{NdMn}_{8.4} \mathrm{Co}_{3.6}$ & $\mathrm{P}$ & & & 3.44 & 7.5 \\
\hline $\mathrm{SmMn}_{3.77} \mathrm{Co}_{8.23}$ & $\mathbf{F}$ & $\approx 500$ & 10.02 & & \\
\hline $\mathrm{SmMn}_{8.71} \mathrm{Co}_{3.29}$ & $\mathrm{~F}$ & $\approx 18$ & 0.59 & & \\
\hline $\mathrm{SmMn}_{3.9} \mathrm{Ni}_{8.1}$ & $\mathrm{~F}$ & $\approx 550-600$ & 9.1 & & \\
\hline
\end{tabular}

$\mathrm{F}$ - ferromagnetic, $\mathrm{C}$ - complex, $\mathrm{AF}$ - antiferromagnetic, $\mathrm{P}$ - paramagnetic.

La compounds, Y compounds provide the reference system for the compounds of the magnetic lanthanides. However, the $\mathrm{Y}$-Mn ternaries have been obtained for $\mathrm{Fe}$ only, and the compound richest in Mn exhibits a complicated stoichiometry. It is a surprising result because a binary $\mathrm{YMn}_{12}$ compound was reported to exist with the interesting magnetic structure below $T_{\mathrm{N}}=120 \mathrm{~K}[10]$. Magnetic data of the $\mathrm{RMn}_{x} \mathrm{~T}_{12-x}$ alloys are collected in Table and their temperature and field characteristics are shown in Figs. 1-7. One can see that the magnetic properties allow to classify these materials into a few groups. As it is seen from Table and Figs. 1, 2 and 3, $\mathrm{CeMn}_{4.96} \mathrm{Fe}_{7.04}, \mathrm{NdMn}_{4} \mathrm{Co}_{8}, \mathrm{SmMn}_{3.77} \mathrm{Co}_{8.23}, \mathrm{SmMn}_{8.71} \mathrm{Co}_{3.29}$ and $\mathrm{SmMn}_{3.9} \mathrm{Ni}_{8.1}$ can be considered as ferromagnetic. Their common feature is the apparent saturation at low temperature (Fig. 1), however, with different values of saturation moment, the lowest one is for $\mathrm{SmMn}_{8.71} \mathrm{Co}_{3.29}$. This low saturation moment corresponds to the lowest Curie point, $T_{\mathrm{C}} \approx 18 \mathrm{~K}$. Other $\mathrm{Sm}$ compounds and $\mathrm{NdMn}_{4} \mathrm{Co}_{8}$ exhibit the Curie point above room temperature but small remanence and not a very high saturation moment does not allow to consider them as magnetic materials for application. Moreover, the $\mathrm{Ce}$ and $\mathrm{Nd}$ compounds show 


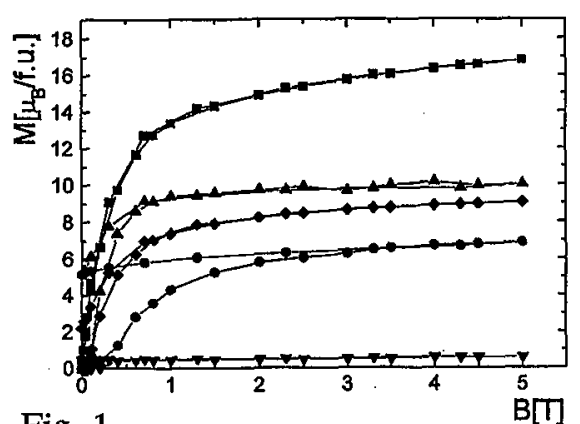

Fig. 1

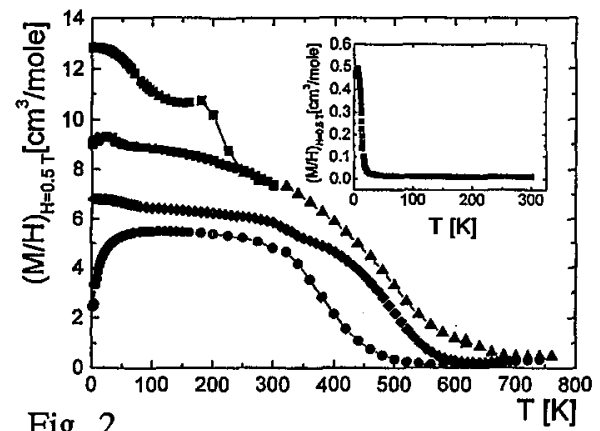

Fig. 2

Fig. 1. Magnetization, $M$, versus magnetic field $B$ at $T=1.7 \mathrm{~K}$ for $\mathrm{CeMn}_{4.96} \mathrm{Fe}_{7.04}$ (squares), $\mathrm{NdMn}_{4} \mathrm{Co}_{8}$ (circles), $\mathrm{SmMn}_{3.77} \mathrm{Co}_{8.23}$ (triangles up), $\mathrm{SmMn}_{8.71} \mathrm{Co}_{3.29}$ (triangles down), and $\mathrm{SmMn}_{3.9} \mathrm{Ni}_{8.1}$ (diamonds).

Fig. 2. Initial susceptibility $(M / H)$ measured at $B=0.5 \mathrm{~T}$ versus temperature for $\mathrm{CeMn}_{4.96} \mathrm{Fe}_{7.04}$ (squares), $\mathrm{NdMn}_{4} \mathrm{Co}_{8}$ (circles), $\mathrm{SmMn}_{3.77} \mathrm{Co}_{8.23}$ (triangles up), and $\mathrm{SmMn}_{3.9} \mathrm{Ni}_{8.1}$ (diamonds). Inset shows the results for $\mathrm{SmMn}_{8.71} \mathrm{Co}_{8.29}$.

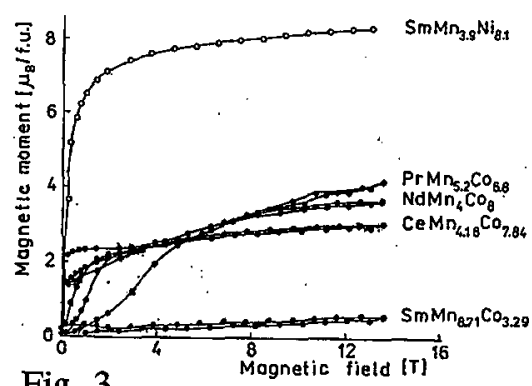

Fig. 3

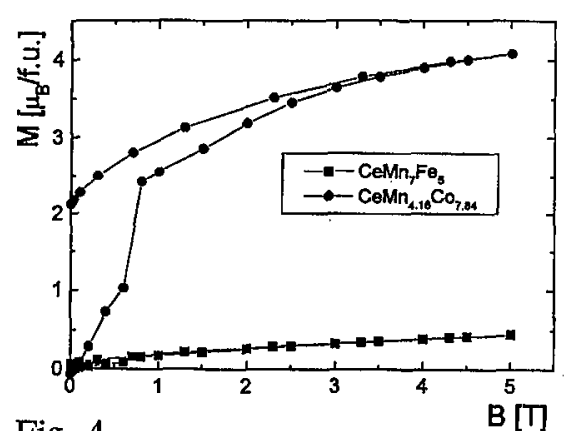

Fig. 4

Fig. 3. Magnetic moment per formula unit, $M$, versus magnetic field up to $14 \mathrm{~T}$ at $T=4.2 \mathrm{~K}$.

Fig. 4. Magnetic moment per formula unit, $M$, versus magnetic field at $T=1.7 \mathrm{~K}$.

complicated temperature dependence of the initial susceptibility (Fig. 2): the first compound exhibits two diffuse drops of the susceptibility, whereas the second one shows the initial increase in susceptibility at low temperature and then the decrease corresponding most probably to the Curie point. The initial increase can be related to the domain effects but also can result from the magnetic ordering more complex than simple ferromagnetic one. The similar $(M / H)$ vs. $T$ characteristics has been reported for the Pr compound [6]. The increase in the magnetic field up to $14 \mathrm{~T}$ at $4.2 \mathrm{~K}$ does not change substantially the data obtained for ferromagnetic $\mathrm{NdMn}_{4} \mathrm{Co}_{8}, \mathrm{SmMn}_{8.71} \mathrm{Co}_{3.29}$ and $\mathrm{SmMn}_{3.9} \mathrm{Ni}_{8.1}$ at $1.7 \mathrm{~K}$. For compounds with complex behavior (Fig. 3): $\mathrm{CeMn}_{4.16} \mathrm{Co}_{7.84}$ and $\mathrm{PrMn}_{5.2} \mathrm{Co}_{6.8}$ the ferromagnetic character of those materials is confirmed (see Fig. 4) in agreement with the results reported for $\mathrm{PrMn}_{4} \mathrm{Co}_{8}$ [6]. The temperature dependence of the 
inverse susceptibility of $\operatorname{PrMn}_{5.2} \mathrm{Co}_{6.8}$ follows the Curie-Weiss law above about $150 \mathrm{~K}$ and for $\mathrm{CeMn}_{7} \mathrm{Fe}_{5}$ above $50 \mathrm{~K}$ (Fig. 5) whereas the magnetization of the last compound is very weakly field dependent at $T=1.7 \mathrm{~K}$ (Fig. 4). Both yttrium compounds $\mathrm{YMn}_{5.1} \mathrm{Fe}_{6.9}$ and $\mathrm{Y}_{1.3} \mathrm{Mn}_{7.9} \mathrm{Fe}_{3.8}$ exhibit also complex magnetic behavior with maxima in temperature dependence of the magnetic susceptibility at low temperature (Table) and this observation does not contradict the result of [2]. The inverse magnetic susceptibility of $\mathrm{YMn}_{5.1} \mathrm{Fe}_{6.9}$ follows the Curie-Weiss law above $250 \mathrm{~K}$ but for three antiferromagnetic Ce compounds the Curie-Weiss law is not fulfilled (Table, Fig. 6). As it is seen from Fig. 7 their magnetization at $1.7 \mathrm{~K}$ is linear, weakly field dependent. Paramagnetic $\mathrm{CeMn}_{9.65} \mathrm{Fe}_{2.35}$ does not follow the Curie-Weiss law (Fig. 6) but $\mathrm{PrMn}_{5.6} \mathrm{Fe}_{6.4}$ exhibits such a behavior (Table, Fig. 5).

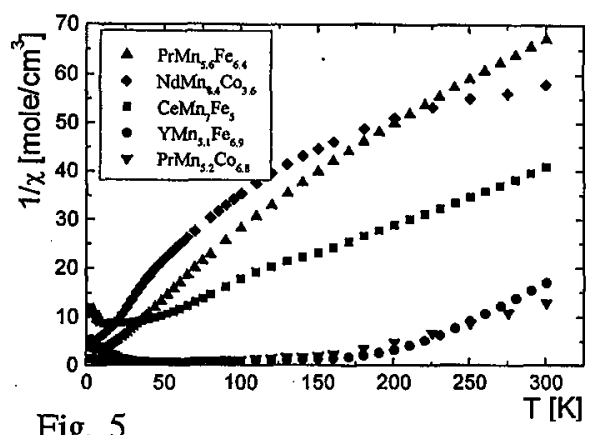

Fig. 5

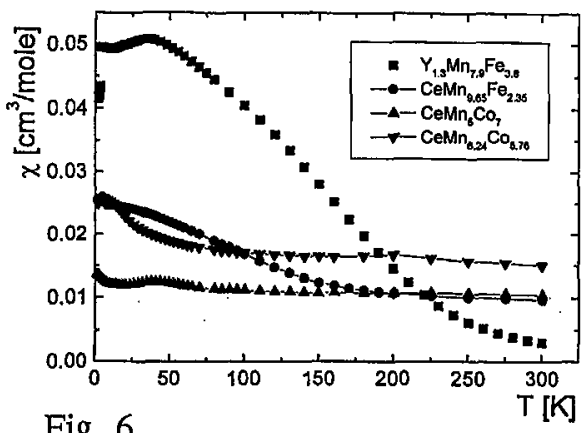

Fig. 6

Fig. 5. Inverse molar magnetic susceptibility, $1 / \chi$, versus temperature, measured at $B=0.5 \mathrm{~T}$.

Fig. 6. Molar magnetic susceptibility, $\chi$, versus temperature, $T=1.7-300 \mathrm{~K}$, at $B=$ $0.5 \mathrm{~T}$.

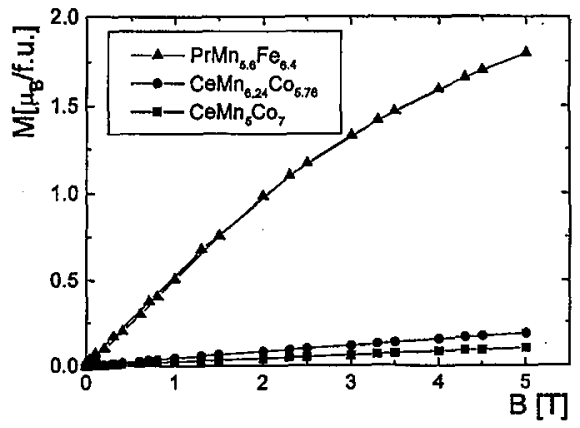

Fig. 7. Magnetic moment per formula unit, $M$, versus magnetic field at $T=1.7 \mathrm{~K}$.

It is clear that an interpretation of these complex magnetic properties of $\mathrm{RMn}_{x} \mathrm{~T}_{12-x}$ alloys is very difficult. The problem of the $f-d$ interaction is under extensive investigation by theoreticians (see e.g. [11]). The magnetization depen- 
dence on magnetic field for the $f-d$ materials has got satisfactory explanation in terms of the molecular field approximation but these models are set up for the two sublattice models [12], and in the $\mathrm{RMn}_{x} \mathrm{~T}_{12-x}$ alloys there could be three magnetic sublattices. Probably, one can propose the following sequence of the magnitude of the exchange interactions $J_{i j}: J_{\mathrm{TT}}>J_{\mathrm{RT}}>J_{\mathrm{RR}}> \pm J_{\mathrm{RMn}} \sim J_{\mathrm{MnMn}}$. However, to prove this statement, further experiments should be done, particularly neutron diffraction. This last experiment can provide also the answer concerning the transition element distribution on the individual crystallographic sites. For example, Abad et al. [5] propose, as mentioned above, competing interactions in $\mathrm{TbMn}_{x} \mathrm{Fe}_{12-x}$ : positive for $\mathrm{Fe}(\mathrm{F})$ and negative for $\mathrm{Mn}(\mathrm{AF})$. They claim that when increasing the $\mathrm{Fe}$ content one observes an increase in ferromagnetic $(\mathrm{F})$ interaction affecting strongly the $3 d$ and $4 f$ moments. The magnetic interactions between the $3 d$ and $\mathrm{Tb}$ ions are considerably stronger than those between $\mathrm{Tb}$ ions, according to the scheme presented above. This feature is responsible for the gradual polarisation of the $\mathrm{Tb}$ magnetic moments when the temperature is lowered. As far as the distribution of the transition elements is concerned, a clear preference for the $\mathrm{Fe}$ atoms to populate the $8 \mathrm{f}$ sites is observed along the series, whereas Mn shows a very strong tendency towards the $8 \mathrm{i}$ sites. However, these conclusions can be justified for $\mathrm{TbMn}_{x} \mathrm{Fe}_{12-x}$ alloys only. There is also a question if magnetic ordering is set up in the Mn sublattice. It seems that the existence and a type of magnetic ordering in this sublattice depends critically on the Mn-Mn separation. Unfortunately, this question cannot be answered properly without neutron diffraction studies.

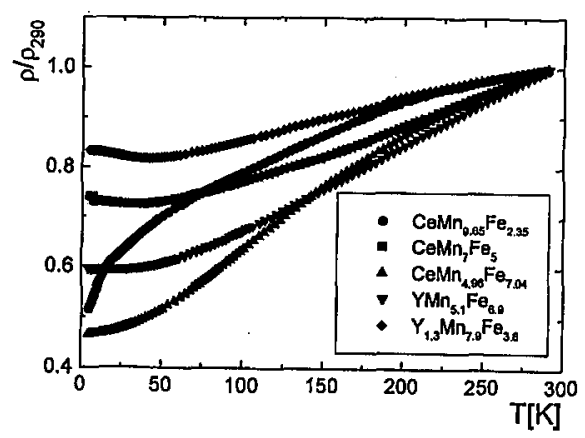

Fig. 8. Electrical resistivity normalized to room temperature value $\rho / \rho_{290}$ versus temperature.

The electrical resistivity normalized to the room temperature value versus temperature for the $\mathrm{Y}$ and Ce alloys is shown in Fig. 8. Generally, the resistivity has a metallic character but except for $\mathrm{CeMn}_{9.65} \mathrm{Fe}_{2.35}$ (paramagnetic) other alloys at low temperature exhibit Kondo-like behavior. 


\section{Conclusions}

1. Some of the $\mathrm{RMn}_{x} \mathrm{~T}_{12-x}$ compounds exhibit the high Curie point and magnetization but rather minute remanence.

2 . The presence of two magnetic $3 d$ transition elements makes an interpretation very difficult.

3. Without the knowledge of the transition elements distribution in three crystallographic positions no conclusive interpretation of magnetic and electrical properties is possible.

\section{References}

[1] W. Suski, in: Handbook on the Physics and Chemistry of Rare Earths, Vol. 22, Eds. K.A. Gschneidner, Jr., L. Eyring, Elsevier, Amsterdam 1996, Ch. 149, p. 143.

[2] Y.C. Yang, B. Kebe, W.J. James, J. Deportes, W. Yelon, J. Appl. Phys. 52, 2077 (1981).

[3] Y. Amako, S. Saoka, H. Yoshie, H. Nagai, K. Adachi, J. Phys. Soc. Jpn. 64, 1860 (1995).

[4] M. Morales, M. Artigas, M. Bacmann, D. Fruchart, J.L. Soubeyroux, P. Wolfers, J. Alloys Comp. 262-263, 134 (1997).

[5] E. Abad, C. Piquè, J.A. Blanco, M. Artigas, R. Burriel, M.T. Fernandes-Diaz, J. Magn. Magn. Mater. 196-197, 745 (1999).

[6] Y.G. Wang, F. Yang, C. Chen, W. Du, P. Lin, X. Zhong, Q. Wang, Phys. Status Solidi A 165, 483 (1998).

[7] R. Verhoef, F.R. de Boer, J.J. M. Franse, C.J.M. Denissen, T.H. Jacobs, K.H.J. Buschow, J. Magn. Magn. Mater. 83, 135 (1990).

[8] B. Belan, W. Suski, K. Wochowski, in: Proc. Moscow Int. Symp. on Magnetism'99, Eds. A. Granovsky, N. Perov, Vol. 1, Moscow State University, Moscow 1999, p. 380.

[9] O.I. Bodak, E.I. Gladyshevskii, Ternary Systems Containing Rare Earth Metals, Spravochnik, Izd. L'vov. Gosuniversiteta, L'vov 1985 (in Russian).

[10] J. Deportes, D. Givord, Solid State Commun. 19, 845 (1976).

[11] M. Richter, J. Phys. D, Appl. Phys. 31, 1017 (1998).

[12] Z.-D. Zhang, M.-H. Yu, T. Zhao, J. Magn. Magn. Mater. 174, 261 (1997); Z.-D. Zhang, T. Zhao, P.F. de Châtel, F.R. de Boer, J. Magn. Magn. Mater. 174, 269 (1997). 